\title{
Neonatal Hypoxia or Maternal Diabetes Delays Postnatal Development of Liver Mitochondria
}

\author{
JUNE R. APRILLE AND MICHAEL T. NOSEK
}

Mitochondrial Physiology Unit, Department of Biology, Tufts University, Medford, Massachusetts 02155

\begin{abstract}
The matrix adenine nucleotide pool size of rat liver mitochondria was low at birth $(2.6-3.0 \mathrm{nmol}$ ATP+ADP+AMP/mg mitochondrial protein). After parturition, the pool size was increased by $50-75 \%$ within 1 $h$, which was sufficient for full development of state 3 respiration rates. The adenine nucleotide pool size continued to increase to $100-150 \%$ of the value at birth by $2-3$ $h$ postnatal. The ATP/ADP ratio in isolated mitochondria also increased postnatally, to about double the value at birth by $3 \mathrm{~h}$. There were no matrix volume changes over this postnatal period, so the increased ATP+ADP+AMP pool size and the increased ATP/ADP ratio together inferred an overall increase of about 5-fold in the matrix ATP concentration under aerobic conditions. The postnatal uptake of adenine nucleotides into mitochondria occurred at a slower rate in newborns that were hypoxic $\left(11 \% 0_{2}\right)$ and in newborns of diabetic mothers (diabetes induced on day 5 of gestation by streptozotocin injection). The normal increase in matrix ATP content is responsible for the rapid stimulation of pyruvate carboxylation (an ATP-requiring matrix reaction) and this in turn contributes to the rapid postnatal onset of gluconeogenesis. The results suggest that delayed adenine nucleotide uptake into liver mitochondria may retard initiation of gluconeogenesis in newborns experiencing hypoxia, as in respiratory distress or in newborns of diabetic mothers. We speculate that this mechanism contributes to the persistent hypoglycemia that is typical of these at-risk newborns. (Pediatr Res 21: 266$269,1987)$
\end{abstract}

Mitochondria isolated from full-term fetal rat liver are functionally well coupled, but the rate of oxidative phosphorylation (state 3 respiration) is very low (reviewed in Reference 1). Within $1 \mathrm{~h}$ after birth, the state 3 rate increases to adult values (2-4). This functional maturation depends on a rapid increase in the mitochondrial adenine nucleotide content (ATP+ADP+AMP) which occurs in the immediate postnatal period $(2,4-6)$ In addition to activating state 3 respiration the increased adenine nucleotide pool size may also stimulate metabolic pathways that have adenine nucleotide-dependent enzymes within the mitochondrial compartment (reviewed in Reference 1). One matrix enzyme subject to this kind of control is pyruvate carboxylase. In both the newborn rat and rabbit the sudden postnatal increase in the matrix ATP concentration enhances pyruvate carboxylation rates enabling the onset of gluconeogenesis and recovery from postnatal hypoglycemia (7-9). Thus, the accumulation of adenine nucleotides into the mitochondria appears to be important for metabolic adaptation to neonatal life (see Reference 1).

Received May 13, 1986; accepted October 23, 1986.

Correspondence and reprint requests Dr. June R. Aprille, Mitochondrial Physiology Unit, Department of Biology, Tufts University, Medford, MA 02155.

Supported by NIH Grants HD 16936 and NS 14936.
There is considerable evidence that hormones and oxygenation are important controlling factors for the subcellular redistribution of adenine nucleotides in newborn liver $(9,10)$ (Tullson PC, Aprille JR, unpublished data). The purpose of this study was to determine whether the normal postnatal increase in mitochondrial adenine nucleotide content is delayed by neonatal hypoxia or by maternal diabetes, because in these conditions arterial $\mathrm{pO}_{2}$ and hormone status, respectively, are usually abnormal $(12,13)$. It is interesting that these groups of newborns experience problematic postnatal hypoglycemia, given that a delay in the maturation of mitochondria would also delay the onset of gluconeogenesis.

\section{METHODS}

Animals. Timed-pregnant Sprague-Dawley rats were purchased from Charles River Breeding Laboratories (Wilmington, MA). To produce maternal diabetes, $45 \mathrm{mg} / \mathrm{kg}$ streptozotocin in

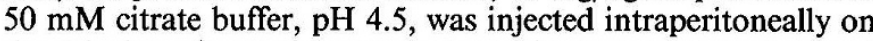
the 5th day of gestation; controls received an equal volume of vehicle. Animals were kept on a 12-h light-dark cycle and allowed food and water ad libitum. Unless otherwise indicated the mothers were killed by decapitation at full term, on the 22 nd day of gestation (mating day was day 0). Newborns were removed by cesarean section and either killed immediately (time 0 ) or placed in a humidified $30^{\circ} \mathrm{C}$ incubator for use at later times. In experiments where percent atmospheric $\mathrm{O}_{2}$ was a variable, the incubator was continuously perfused with specific gas mixtures. For the streptozotocin-treated mothers and controls, blood was tested immediately after decapitation with glucose test strips (Chemstrip bG, Boehringer-Mannheim, Indianapolis, IN) to confirm maternal diabetes before the litters were pooled for the experiment. Additional blood was collected for quantitative detemination of serum glucose at a later time using the glucose oxidase method (Sigma, St. Louis, MO).

Mitochondria. Eight to 16 pups were pooled for the isolation of liver mitochondria by differential centrifugation as previously described (2). Mitochondria were suspended to about $10 \mathrm{mg}$ protein $/ \mathrm{ml}$ in $0.25 \mathrm{M}$ sucrose and $1 \mathrm{mM}$ Tris-HCl. The exact protein concentration was determined by the Lowry et al. (14) method.

Adenine nucleotides. Aliquots of the mitochondrial suspensions were extracted with perchloric acid and neutralized prior to the determination of ATP, ADP, and AMP by enzymatic methods $(2,15,16)$.

Other assays. Mitochondrial matrix spaces were calculated as the difference between the ${ }^{3} \mathrm{H}$-water and ${ }^{14} \mathrm{C}$-sucrose volumes of the mitochondrial pellet $(17,18)$. Cytochrome oxidase activity was determined spectrophotometrically after adding Triton X100 (f.c. $0.01 \%$ ) to the mitochondrial suspensions (19). Respiratory rates for intact mitochondria were determined polarographically with either glutamate + malate $(5 \mathrm{mM}$ each) or succinate $(10 \mathrm{mM})$ as the substrate. ADP was used to elicit state 3 rates and 2,4-dinitrophenol was used to elicit uncoupled rates all as previously described (2). 


\section{RESULTS}

Perinatal changes in mitochondrial adenine nucleotide content and respiration rates. The adenine nucleotide content of rat liver mitochondria during late gestation and early neonatal life is shown in Figure 1. Low values were found in the fetus; an increase ensued upon delivery and continued rapidly for about $2 \mathrm{~h}$. The matrix volume remained constant over this time; the matrix ATP/ADP ratio (measured under state 4 energized conditions) increased with postnatal age (Table 1). Altogether the increase in total adenine nucleotides, increased ATP/ADP ratio, and constant matrix space inferred that there was an approximate 5-fold increase in the matrix ATP concentration within a few hours after birth.

A developmental increase in state 3 respiration has been documented before $(2,3)$ but is shown here in more detail (Fig. 2 ). The maturation of state 3 depends on the increased matrix adenine nucleotide pool size $(2,5,6)$. Throughout this period uncoupled respiration (a measure of electron transport chain activity) remained relatively constant (Fig. 2) as did cytochrome oxidase activity (an index of relative purity of the preparations) (not shown).

Postnatal hypoxia. The rate at which mitochondrial adenine nucleotide content increased postnatally was delayed by hypoxia

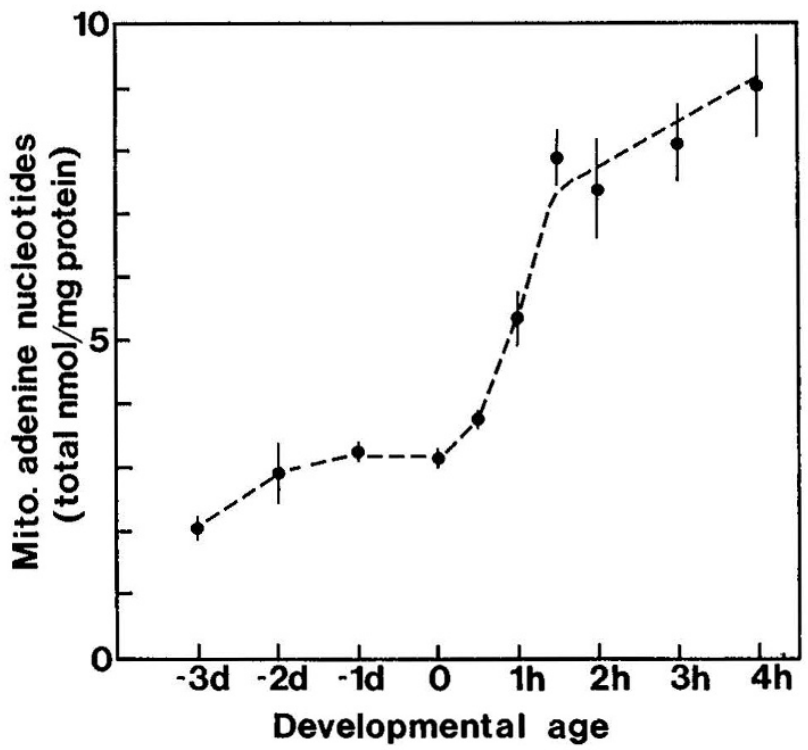

Fig. 1. Total adenine nucleotide content (ATP+ADP+AMP) of mitochondria from rat liver as a function of developmental age in the perinatal period. Ages noted as negative numbers $(-3 d,-2 d,-1 d)$ are for pups delivered 3-, 2-, or 1-day permature relative to 0 which corresponds to full term ( 22 days gestation); all these pups were killed within 2 min of birth. Ages noted as 1 to $4 \mathrm{~h}$ are for pups delivered at full term and killed after 1 to $4 \mathrm{~h}$ of postnatal life.

Table 1. Matrix volume and ATP/ADP ratios in liver mitochondria as a function of postnatal age*

\begin{tabular}{|c|c|c|c|}
\hline \multirow[b]{2}{*}{$\begin{array}{c}\text { Age } \\
\text { (h) }\end{array}$} & \multicolumn{2}{|c|}{$\begin{array}{l}\text { Matrix space }(\mu \mathrm{l} / \mathrm{mg} \\
\text { mitochondrial protein })\end{array}$} & \multirow[b]{2}{*}{$\begin{array}{l}\text { ATP/ADP } \\
\text { ratio } \dagger\end{array}$} \\
\hline & $\begin{array}{l}\text { Respiration } \\
\text { medium }\end{array}$ & Sucrose-Tris & \\
\hline 0 & $1.01 \pm 0.43(4)$ & $1.32 \pm 0.48$ & $1.48 \pm 0.32(4)$ \\
\hline 1 & $1.06 \pm 0.07$ & $1.30 \pm 0.15$ & $2.28 \pm 0.32$ \\
\hline 3 & $0.97 \pm 0.06$ & $1.50 \pm 0.16(3)$ & $3.30 \pm 0.63(3)$ \\
\hline
\end{tabular}

$*$ Values are mean $\pm \mathrm{SE}$ for the number of experiments in parentheses.

$\dagger$ Determined in respiratory medium under state 4 conditions with glutamate + malate as substrate.

$\ddagger$ Different $(p<0.05)$ from $0 \mathrm{~h}$ value by one-way analysis of variance.

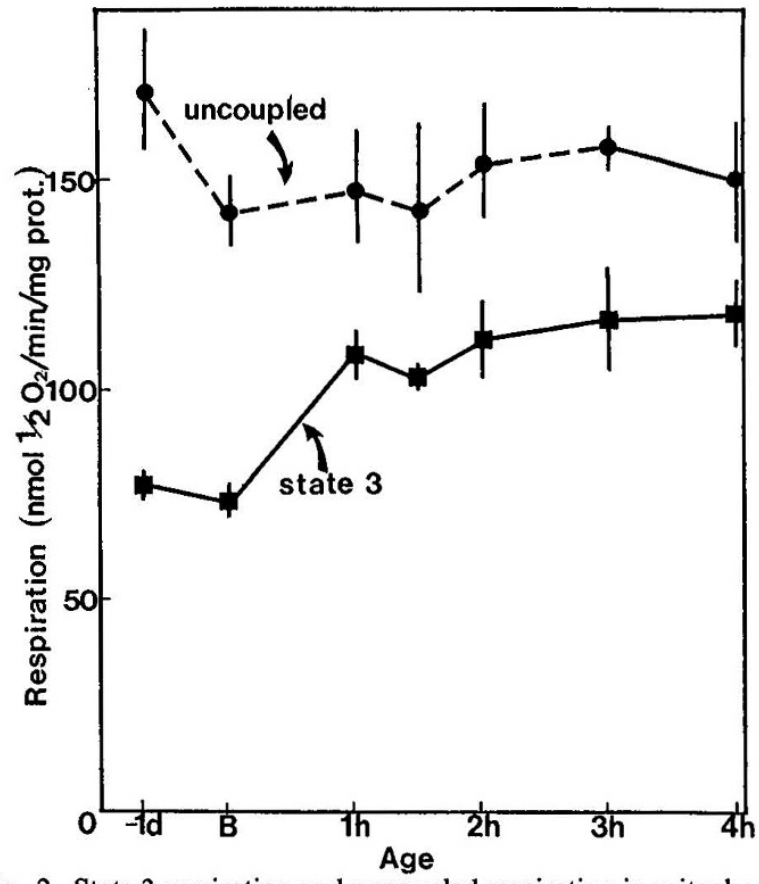

Fig. 2. State 3 respiration and uncoupled respiration in mitochondria of rat liver as a function of developmental age in the immediate postnatal period. Ages are designated as described in legend of Figure 1 except that B is used instead of 0 to designate pups delivered at full term and killed immediately.

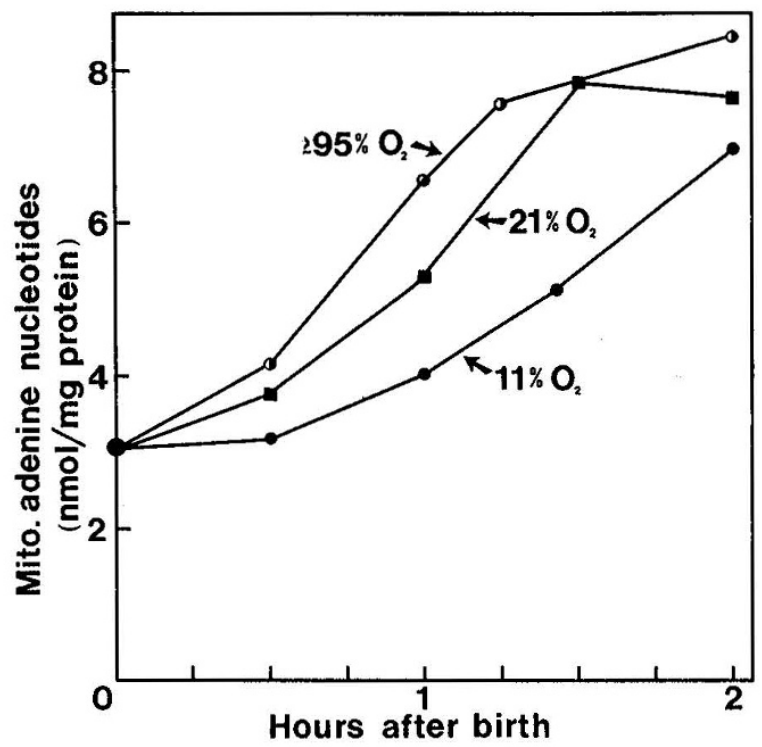

Fig. 3. Total adenine nucleotide content (ATP+ADP+AMP) of liver mitochondria from newborn rats kept under atmospheres of different $\%$ $\mathrm{O}_{2}$ from birth. Data points represent several separate determinations. SE are not shown for simplification, but representative values for adenine nucleotides are as follows: at $1 \mathrm{~h}, 6.6 \pm 0.4$ for $n=6$ animals in $>95 \%$ $0_{2} ; 5.3 \pm 0.4$ for $n=7$ in air; $4.0 \pm 0.2$ for $n=6$ in $11 \% 0_{2}$. These values for $>95 \% 0_{2}$ and $11 \% 0_{2}$ were different from air to $p<0.03$ and 0.01 ,

(Fig. 3). Hyperoxia may have enhanced the adenine nucleotide increase compared to air (Fig. 3), but this effect was variable (compare Table 2 and Fig. 3 for values at $1 \mathrm{~h}$ postnatal) and probably not significant. The normal postnatal increase in state 3 respiration rate also was delayed by hypoxia, but was unaffected by hyperoxia (Table 2 ). The mitochondrial matrix volume was not differentially affected by hypoxia or hyperoxia (Table 2 ). 
Table 2. Effect of atmospheric $\mathrm{pO}_{2}$ on the postnatal development of liver mitochondria*

\begin{tabular}{|c|c|c|c|c|c|}
\hline \multirow{2}{*}{$\begin{array}{l}\text { Age } \\
\text { (h) }\end{array}$} & \multirow{2}{*}{$\begin{array}{c}\text { Atmosphere } \\
\left(\% \mathrm{O}_{2}\right) \\
\end{array}$} & \multirow{2}{*}{$\begin{array}{c}\mathrm{ATP}+\mathrm{ADP}+\mathrm{AMP} \\
\text { (nmol/mg protein) }\end{array}$} & \multicolumn{2}{|c|}{$\begin{array}{c}\text { Respiratory rates } \\
\text { (nmol } 1 / 2 \mathrm{O}_{2} / \mathrm{min} / \mathrm{mg} \text { protein) }\end{array}$} & \multirow{2}{*}{$\begin{array}{l}\text { Matrix volume } \\
(\mu \mathrm{l} / \mathrm{mg} \text { protein })\end{array}$} \\
\hline & & & State 3 & 2,4 DNP & \\
\hline 1 & $11 \% \mathrm{O}_{2}$ & $3.77 \pm 0.26(3) \dagger$ & $84 \pm 7(3) \dagger$ & $175 \pm 24(3)$ & $0.71 \pm 0.27(3)$ \\
\hline 1 & $\operatorname{Air}\left(21 \% \mathrm{O}_{2}\right)$ & $5.66 \pm 0.59(7)$ & $108 \pm 6(5)$ & $148 \pm 14(5)$ & \\
\hline 1 & $100 \% \mathrm{O}_{2}$ & $5.89 \pm 0.57(3)$ & $120 \pm 12(3)$ & $147 \pm 15$ & $0.78 \pm 0.43(3)$ \\
\hline
\end{tabular}

* Newborns were either killed at birth (age $0 \mathrm{~h}$ ) or placed in incubators with atmospheres of different \% $\mathrm{O}_{2}$ and killed $1 \mathrm{~h}$ later. Liver mitochondria were isolated and assayed for adenine nucleotides, respiratory rates, and matrix volumes as described under Methods. The respiratory substrate was glutamate + malate. Matrix volumes and adenine nucleotides were determined for mitochondria suspended in sucrose-Tris medium with no substrate. Values are mean $\pm \mathrm{SE}$ for the number of experiments in parentheses.

$\uparrow$ Different $(p<0.05)$ from value at $1 \mathrm{~h}$ in air by unpaired Student's $t$ test (one-tailed).

Table 3. Effect of maternal diabetes on postnatal development of liver mitochondria in newborn rat*

\begin{tabular}{|c|c|c|c|c|c|c|}
\hline \multirow{3}{*}{$\begin{array}{l}\text { Age } \\
\text { (h) }\end{array}$} & \multicolumn{2}{|c|}{$\begin{array}{c}\text { Mitochondrial } \\
\text { ATP + ADP + AMP } \\
\text { (nmol/mg protein) }\end{array}$} & \multicolumn{4}{|c|}{$\begin{array}{c}\text { Respiratory rates } \\
\text { (nmol } 1 / 2 \mathrm{O}_{2} / \mathrm{min} / \mathrm{mg} \text { protein) }\end{array}$} \\
\hline & \multirow[b]{2}{*}{ Control } & \multirow[b]{2}{*}{ Diabetic } & \multicolumn{2}{|c|}{ State 3} & \multicolumn{2}{|c|}{$2,4 \mathrm{DNP}$} \\
\hline & & & Control & Diabetic & Control & Diabetic \\
\hline $0(2)$ & $2.57 \pm 0.14$ & $2.56 \pm 0.33$ & $74 \pm 2$ & $81 \pm 4$ & $130 \pm 4$ & $131 \pm 3$ \\
\hline $1(3)$ & $3.76 \pm 0.44$ & $3.28 \pm 0.44$ & $106 \pm 1$ & $109 \pm 4$ & $123 \pm 10$ & $135 \pm 12$ \\
\hline $2(4)$ & $5.40 \pm 0.54$ & $3.98 \pm 0.42 \dagger$ & $114 \pm 12$ & $111 \pm 9$ & $139 \pm 16$ & $136 \pm 11$ \\
\hline
\end{tabular}

* Newborns from diabetic and control females (maternal serum glucose was $410 \pm 39$ and $96 \pm 6 \mathrm{mg} / \mathrm{dl}$, respectively) were killed at birth $(0 \mathrm{~h}$ ), or at 1 , or $2 \mathrm{~h}$ postnatal for isolation of liver mitochondria. Respiratory rates (with glutamate + malate as substrate) and adenine nucleotide content (ATP + ADP + AMP) were determined, all as described in "Methods." Values are mean \pm SE for the number of experiments in parentheses, except when $n=2$, values are mean \pm limits of range.

$\dagger p<0.05$ compared to control by unpaired Student's $t$ test (one-tailed).

Maternal diabetes. The rate at which the liver mitochondrial adenine nucleotide content increased in newborns of diabetic mothers was somewhat slower than in controls; a statistically significant difference in the pool size became apparent at $2 \mathrm{~h}$ postnatal (Table 3). There was no effect of maternal diabetes on the maturation of state 3 respiration which requires only a small increase in adenine nucleotide content and which is normally complete by $1 \mathrm{~h}$ (Table 3 ).

\section{DISCUSSION}

A marked postnatal increase in the adenine nucleotide content of liver mitochondria has been demonstrated in the rat (2-4), rabbit $(9,20)$, and guinea pig (21). A small initial increase appears to be necessary for the maturation of state 3 respiration rates in some species. In the rat, state 3 respiration rates developed to a maximum by $1 \mathrm{~h}$ after birth (Fig. 1) when the adenine nucleotide content of mitochondria had increased by only $50-75 \%$. The development of state 3 respiration rates can be mimicked by loading isolated newborn rat liver mitochondria with adenine nucleotides in vitro (5). Conversely, if mature mitochondria are depleted of adenine nucleotides in vitro to levels approximating the pool size of newborn mitochondria, state 3 respiration is decreased to newborn rates (22). Thus, a cause-effect relationship between modest postnatal increases in the matrix adenine nucleotide content and the development of state 3 respiration within the $1 \mathrm{st} \mathrm{h}$ after birth has been firmly established for rat.

In rabbit the matrix adenine nucleotide pool size at birth is higher than it is in the rat and state 3 respiration is fully developed (20). Nevertheless the pool size in rabbit increases 2- to 3-fold within $2 \mathrm{~h}$ after birth just as it does in rat. These large increases in mitochondrial adenine nucleotide content are far in excess of the threshold required for expression of maximum rates of respiration. Moreover, in both the rat and rabbit there is a concomitant developmental increase in the matrix ATP/ADP ratio measured under energized conditions in vitro. In this study, for example, the adenine nucleotide pool size of rat liver mitochondria increased about 2.5 -fold and the in vitro ATP/ADP ratio was increased about 2 -fold by $2-3 \mathrm{~h}$ after birth. Since there was no change in mitochondrial matrix volume, the increased pool size and ATP/ADP ratio together infer a 4- to 5-fold increase in matrix ATP concentration that has the potential to stimulate ATP-requiring metabolic reactions within the mitochondria (1).

The pyruvate carboxylase reaction is a candidate for this type of regulation since the enzyme is localized to the mitochondrial matrix. In previous work the postnatal increase in the matrix ATP content was shown to stimulate pyruvate carboxylation (7, $8)$, which is rate-limiting for gluconeogenesis at birth $(9,23)$. Herein we have shown that adenine nucleotide accumulation by mitochondria is delayed by neonatal hypoxia and in pups of diabetic mothers; this delay may retard the rapid onset of gluconeogenesis and thus contribute to the problematic postnatal hypoglycemia that is characteristic of these groups of newborns $(12,13,24)$.

Relative hypoxia was shown previously to delay the developmental increase in mitochondrial adenine nucleotide content in rabbit liver (9) (Tullson PC, Aprille JR, unpublished data), but in the rat only the extreme condition of total anoxia in 1-day premature animals has been examined (10). Herein we showed that the rate of adenine nucleotide accumulation into the matrix is affected by modest hypoxia. In $11 \% \mathrm{O}_{2}$ adenine uptake was slow enough to delay the maturation of state 3 respiration, which is normally complete within $1 \mathrm{~h}$ when the adenine nucleotide pool size has increased by only $50-75 \%(2,5,20)$. In newborn rabbits, postnatal hypoxia can cause the adenine pool size to decrease below birth levels with a concomitant decrease in pyruvate carboxylation rates (9). In adult rats, hypoxic perfusion of the liver results in a decrease in the mitochondrial adenine nucleotide content and in state 3 respiration $(25,26)$.

The streptozotocin model for maternal diabetes used herein 
has been well characterized; maternal weight gain is the same as in controls and newborn weights are decreased only slightly (24). The slower rate of adenine nucleotide uptake into liver mitochondria in pups of diabetic mothers that we observed is probably due to the higher than normal insulin/glucagon ratio in these newborns $(24,27)$ (Tullson PC, Aprille JR, unpublished data). Glucagon, epinephrine, or dibutyryl-cyclic-AMP injected into 1day preterm rats delivered by cesarean-section causes a slight but significant increase in the adenine nucleotide content of liver mitochondria (10). Insulin inhibits and glucagon stimulates mitochondrial adenine nucleotide accumulation in full-term newborn rabbits (9) (Tullson PC, Aprille JR, unpublished data). The insulin/glucagon ratio influences the adenine nucleotide pool size in adult rat liver mitochondria also (28-33).

It is difficult to study hormones and oxygenation as separate variables in vivo. For example, maternal diabetes may impair lung maturation $(34,35)$, so that relative hypoxia may contribute to the delay in mitochondrial adenine nucleotide uptake in the newborns. Furthermore, hypoxia stimulates catecholamine secretion (36). Nevertheless, the evidence clearly shows that both oxygenation and hormone status should be considered in the design of rational treatment for these at-risk newborns (9) (Tullson PC, Aprille JR, unpublished data). For example, glucose is given to protect the brain in postnatal hypoglycemia, but glucose also inhibits glucagon secretion and stimulates insulin secretion and may actually delay development of the newborn's ability to independently regulate glucose homeostasis by the mechanisms disclosed in this study.

The exact biochemical mechanisms by which hormones and oxygen affect the subcellular redistribution of adenine nucleotides is not yet known. Uptake into the mitochondria occurs over a specific transporter that mediates the accumulation of ATP-Mg in exchange for matrix $P_{i}$ (37). The net uptake of ATP$\mathrm{Mg}$ against a concentration gradient is energy dependent and the requirement for adequate oxygenation may reflect the need for a protonmotive force across the inner mitochondrial membrane (17). Postnatal increases in the cytosolic ATP/ADP ratio $(4,9$, 23) may also be important in providing the favored substrate (ATP-Mg versus ADP-Mg) for the transporter (38). The normal increase in the tissue ATP/ADP ratio is prevented in pups of diabetic mothers $(39)$ or by insulin injection $(9,39)$.

In summary, this study suggests that neonates with respiratory distress and those born to diabetic mothers experience a delay in the postnatal uptake of adenine nucleotides by liver mitochondria. This probably results in a failure to activate gluconeogenesis immediately after birth and may contribute to the prolonged hypoglycemia that is typical of these groups of newborns.

Acknowledgment. The authors thank Caroline Brown for excellent technical assistance.

\section{REFERENCES}

1. Aprille JR 1986 Perinatal development of mitochondria in rat liver. In: Fiskum G (ed) Physiology and Pathology of Mitochondria. Van Nostrand-Reinhold, Stroudsburg, PA, pp 66-99

2. Aprille JR, Asimakis GK 1980 Postnatal development of rat liver mitochondria: state 3 respiration, adenine nucleotide translocase activity, and net accumulation of adenine nucleotides. Arch Biochem Biophys 201:564-575

3. Nakazawa T, Asami H, Suzuki H, Yukawa O 1973 Appearance of energy conservation system in rat liver mitochondria during development. The role of adenine nucleotide translocation. J Biochem (Tokyo) 73:397-406

4. Sutton R, Pollak JK 1978 The increasing adenine nucleotide concentration and the maturation of liver mitochondria during neonatal development. Differentiation 12:15-21

5. Aprille JR 1981 Net uptake of adenine nucleotides by newborn rat liver mitochondria. Arch Biochem Biophys 207:157-164

6. Baggetto L, Gautheron DC, Godinot C 1984 Effects of ATP on various steps controlling the rate of oxidative phosphorylation in newborn rat liver mitochondria. Arch Biochem Biophys 232:670-678

7. Aprille JR, Yaswen P, Rulfs J 1981 Acute postnatal regulation of pyruvate carboxylase activity by compartmentation of mitochondrial adenine nucleotides. Biochim Biophys Acta 675:143-147

8. Brennan WA Jr, Aprille JR 1984 Regulation of hepatic gluconeogenesis by rapid compartmentation of mitochondrial adenine nucleotides in the newborn rabbit. Comp Biochem Physiol 77B:35-39

9. Brennan WA Jr, Aprille JR 1985 Regulation of hepatic gluconeogenesis in newborn rabbit: Controlling factors in presuckling period. Am J Physio 249:E498-E505

10. Sutton R, Pollak JK 1980 Hormone-initiated maturation of rat liver mitochondria after birth. Biochem J 186:361-367

11. Deleted in proof.

12. Ktorza A, Bihoreau M-T, Nurjhan N, Picon L, Girard J 1985 Insulin and glucagon during the perinatal period: Secretion and metabolic effects on the liver. Biol Neonate 48:204-220

13. Ballard FJ 1978 Carbohydrate metabolism and the regulation of blood glucose. In: Stave U (ed) Perinatal Physiology. Plenum Medical Book Co., New York, pp 365-381

14. Lowry OH, Rosebrough NJ, Farr AL, Randall RJ 1951 Protein measurement with the Folin phenol reagent. J Biol Chem 193:265-275

15. Lamprecht $\mathrm{W}$, Trautschold I 1974 Adenosine-5'-triphosphate: determination with hexokinase and glucose-6-phosphate dehydrogenase. In: Bergmeyer HU (ed) Methods of Enzymatic Analysis, Vol. 4. Academic Press, New York, pp 2101-2110

16. Jaworek D, Gruber W, Bergmeyer HU 1974 Adenosine-5'-diphosphate and adenosine-5'-monophosphate. In: Bergmeyer HU (ed) Methods of Enzymatic Analysis, Vol. 4. Academic Press, New York, pp 2127-2131

17. Aprille JR, Austin J 1981 Regulation of the intramitochondria ATP+ADP+AMP pool size. Arch Biochem Biophys 212:689-699

18. Rottenberg $\mathrm{H} 1979$ The measurement of membrane potential and $\Delta \mathrm{pH}$ in cells, organelles, and vesicles. In: Fleischer S, Packer L (eds) Methods in Enzymology, Vol. LV. Academic Press, New York, pp 547-569

19. Wharton DC, Tzagoloff A 1967 Cytochrome oxidase from beef heart mitochondria. In: Estabrook RW, Pullman ME (eds) Methods in Enzymology, Vol. X. Academic Press, New York, pp 245-250

20. Rulfs J, Aprille JR 1982 Adenine nucleotide pool size, adenine nucleotide translocase activity, and respiratory activity in newborn rabbit liver mitochondria. Biochim Biophys Acta 681:300-304

21. Hale DE, Williamson JR 1984 Developmental changes in the adenine nucleotide translocase in the guinea pig. J Biol Chem 259:8737-8742

22. Asimakis GK, Aprille JR 1980 In vitro alteration of the size of the liver mitochondrial adenine nucleotide pool: correlation with respiratory functions. Arch Biochem Biophys 203:307-316

23. Ballard FJ 1971 The development of gluconeogenesis in rat liver: controlling factors in the newborn. Biochem J 124:265-271

24. Cuezva JM, Burkett ES, Kerr DS, Rodman HM, Patel MS 1982 The newborm of diabetic rat. I. Hormonal and metabolic changes in the postnatal period. Pediatr Res 16:632-637

25. Nakazawa T, Nunokawa T 1977 Energy transduction and adenine nucleotides in mitochondria from rat liver after hypoxic perfusion. J Biochem (Tokyo) 82:1575-1583

26. Watanabe $F$, Kamiike W, Nishimura T, Hashimoto T, Tagawa K 1983 Decrease in mitochondrial levels of adenine nucleotides and concomitant mitochondrial dysfunction in ischemic rat liver. J Biochem (Tokyo) 94:493499

27. Sperling MA 1978 Insulin and glucagon. In: Stave U (ed) Perinatal Physiology Plenum Medical Book Co., New York, pp 813-829

28. Siess EA, Brocks DG, Lattke HK, Wieland OH 1977 Effect of glucagon on metabolite compartmentation in isolated rat liver cells during gluconeogenesis from lactate. Biochem J 166:225-235

29. Pipric V, Spencer TL, Bygrave FL 1978 Stable enhancement of calcium retention in mitochondria isolated from rat liver after the administration of glucagon to the intact animal. Biochem J 176:705-714

30. Hensgens H, Verhoeven AJ, Meijer AJ 1980 The relationship between intramitochondrial $\mathrm{N}$-acetylglutamate and activity of carbamoyl-phosphate synthetase (ammonia). Eur J Biochem 107:197-205

31. Titheradge MA, Haynes RC Jr 1980 The control of uncoupler-activated ATPase activity in rat liver mitochondria by adenine nucleotide transport. Biol Chem 255:1471-1477

32. Aprille JR, Nosek MT, Brennan WA Jr 1982 Adenine nucleotide content of liver mitochondria increases after glucagon treatment of rats or isolated hepatocytes. Biochem Biophys Res Commun 108:834-839

33. Tullson PC, Aprille JR 1986 Increased adenine nucleotides in liver mitochondria after mannoheptulose injection in vivo. Arch Biochem Biophys 246:611616

34. Robert MF, Neff RK, Hubbell JP, Taeusch J, Avery ME 1976 Association between maternal diabetes and the respiratory-distress syndrome in the newborn. N Engl J Med 294:357-360

35. Bose CL, Manne DM, D'Ercole AJ, Lawson EE 1980 Delayed fetal pulmonary maturation in a rabbit model of the diabetic pregnancy. J Clin Invest 66:220 226

36. Girard JR, Zeghal N 1975 Adrenal catecholamine content in fetal and newborn rats. Biol Neonate 26:205-213

37. Austin J, Aprille JR 1984 Carboxyatractyloside-insensitive influx and efflux of adenine nucleotides in rat liver mitochondria. J Biol Chem 259:154-160

38. Austin J, Aprille JR 1983 Net adenine nucleotide transport in rat live mitochondria is affected by both the matrix and external ATP/ADP ratios. Arch Biochem Biophys 222:321-325

39. Cuezva JM, Patel MS 1985 Effect of glucose and insulin administration on hepatic adenylate energy charge and the cytosolic redox state in the neonates of normal and insulin-treated diabetic rats. Biol Neonate 48:221-227 